\title{
Reconstruction of Severe Nasal Septum Deformity
}

\author{
Yakup Cil*
}

Department of Plastic Surgery, Ataturk Training and Research Hospital, Ankara, Turkey

*Corresponding Author:

Yakup Cil, MD;

Associate Professor of Department of Plastic Surgery,

Ataturk Training and Research Hospital, Ankara, Turkey.

Email: yakupcil@yahoo.com

Received: May 25, 2017

Revised: January 18, 2018

Accepted: February 2, 2018

\section{DEAR EDITOR}

Different surgical techniques have been described for treatment of severe nasal septum deformities. ${ }^{1-4}$ We used iliac bone with costal cartilage graft for Tessier No O nose deformity. A 22-yearold male patient admitted to our clinic due to severe functional and aesthetic nasal problems (Figure 1). Physical examination showed that the nasal septum was severely distorted. Nasal structures were exposed through an open rhinoplasty approach under patient general anesthesia. Septal cartilage sculpturing was not possible and distorted cartilage septum remnant was removed. Rigid iliac bone graft and costal cartilage was taken and prepared like as sandwich for nasal septum reconstruction (Figure 2).

Duration of the operation was three hours. After closure, nasal packing was applied. The packing and the nasal splint were removed at 3th and 7th days, respectively. Patient has recovered without problems. No donor site complication has been observed. Aesthetic and functional results were acceptable (Figure 3). Different techniques have been described in the literature for severe nose deformity corrections. ${ }^{1-8}$ In the management of this case; iliac bone graft with costal cartilage has been used for reconstruction of severe nasal septum deformity. The bone and cartilage combination may be used in selected nose deformity cases.
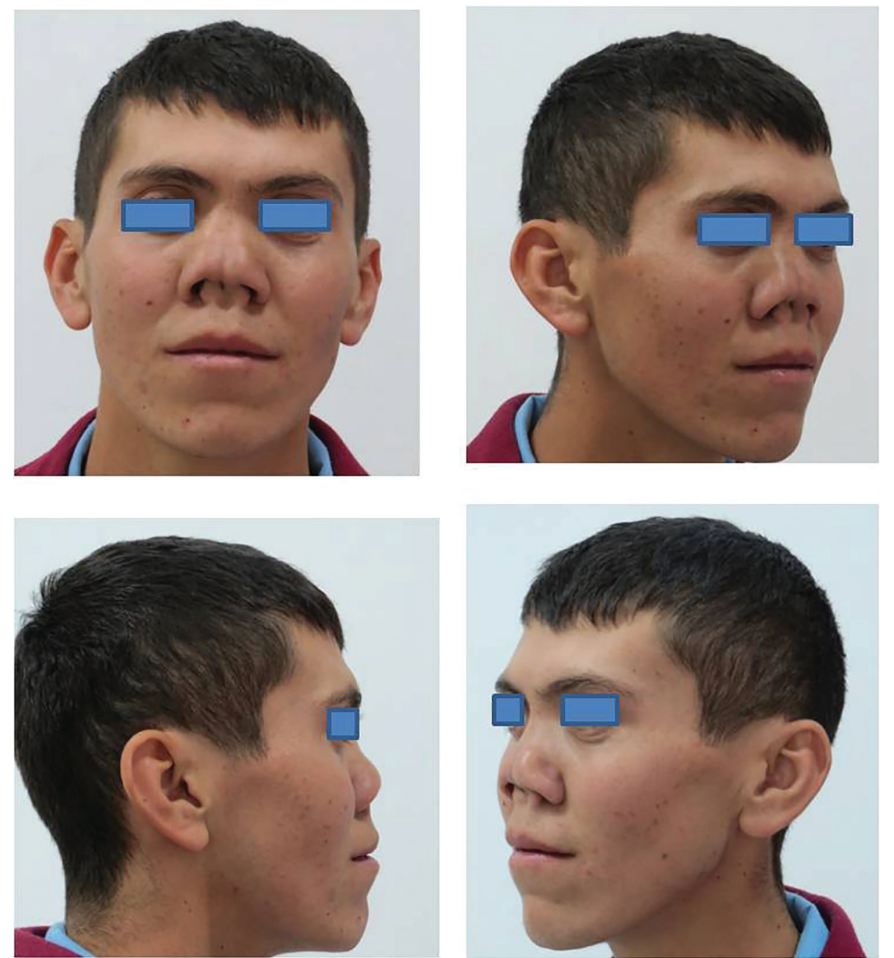

Fig. 1: Preoperative views of the patient with Tessier No 0 nose deformity. 

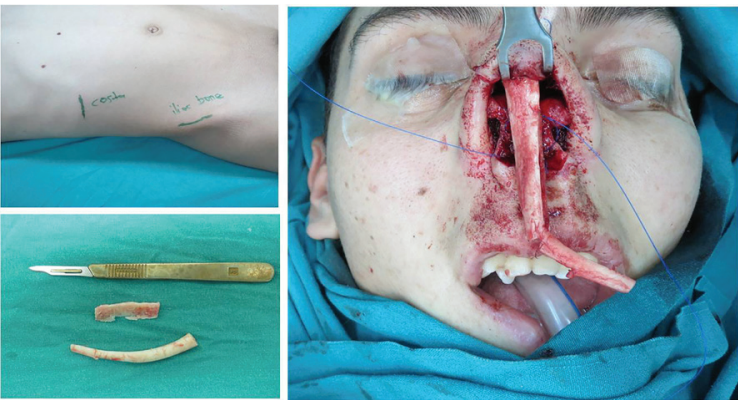

Fig. 2: İliac bone and costal cartilage taken site views. İliac bone was inset in costal cartilage as sandwich before nasal placement.

\section{CONFLICT OF INTEREST}

The authors declare no conflict of interest.

\section{KEYWORDS}

Reconstruction; Nasal septum; Deformity

Please cite this paper as:

Cil Y. Reconstruction of Severe Nasal Septum Deformity. World J Plast Surg 2018;7(3):385-386. doi: 10.29252/wips.7.3.385.

\section{REFERENCES}

1 Cil Y, Ozturk S, Kocman AE, Isik S, Sengezer $M$. The crooked nose: the use of medial iliac crest bone graft as a supporting framework. J Craniofac Surg 2008;19:1631-8.

2 Cil Y, Kocman AE, Yapici AK, Ozturk S. Radial bone graft usage for nasal septal reconstruction. Indian J Plast Surg 2011;44:3640.

3 Yakup Cil. The Surgical Management of The Crooked Nose. 941-947.Atlas of Operative Otorhinolaryngology and Head \& Neck Surgery, Jaypee Brothers Medical Publishers(P) Ltd. 2013.
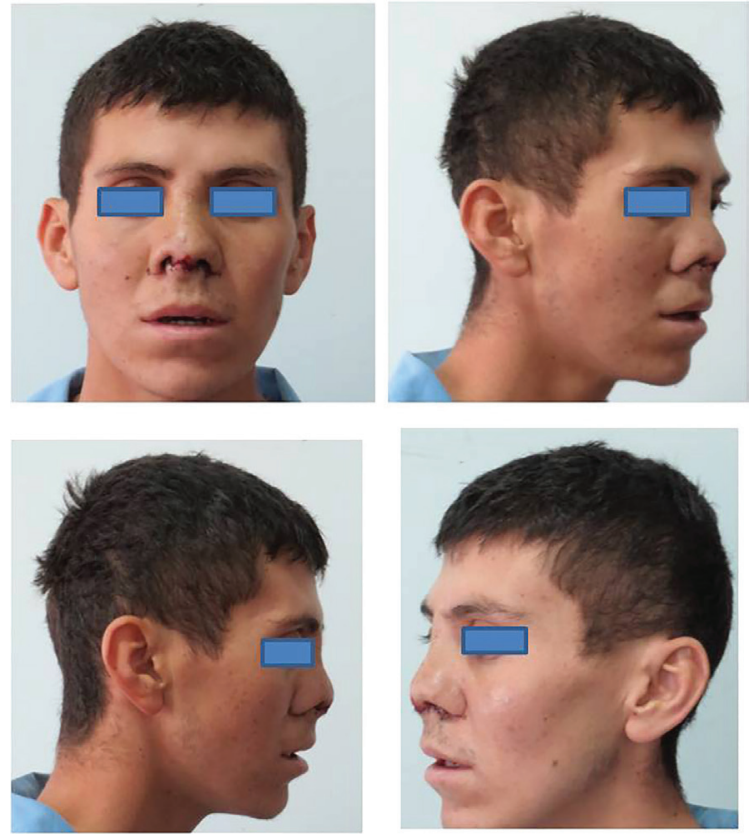

Fig. 3: Postoperative views of the nose.

4 Cil Y. Fibular Bone Graft For Nasal Septal Reconstruction: A Case Report. World J Plast Surg 2017;6:220-224.

5 Guyuron B, Uzzo CD, Scull H. A practical classification of septonasal deviation and an effective guide to septal surgery. Plast Reconstr Surg 1999;104:2202-9.

6 Byrd HS, Salomon J, Flood J. Correction of the crooked nose. Plast Reconstr Surg 1998;102:2148-57.

7 Ozdogan F, Ozel HE, Esen E, Baser S, Genc S, Selcuk A. Nasal septum and external nasal deformity similarities in monozygotic twins and paranasal computed tomography analysis. World J Plast Surg 2018;7:2-4. [1n Press]

8 Panse N, Sahasrabudhe P, Dhondge R. Complex nasal and periorbital reconstruction using locoregional flaps: a case report. World J Plast Surg 2012;1:116-120. 